By ceeptance of this article, tis publisher $c^{\prime}$ res:lpiant fisknowledges the U.S. Governmeni' rizut to retain a non - exchisive, royalty - fre license in and to any copyright covering th articks.-

MOIJELS FOR 1MPURITY PROEUCTION RID TRAMSPOFT IN TOKAMAKS J. T. Hogan

Oak Ridge National Laboratory Oak Rldge, Tennessee 37830, USA
This report wis prepered at an scosunt of work the Untied Slated nor the United Sunte Enero

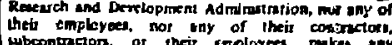

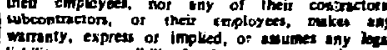

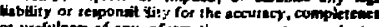

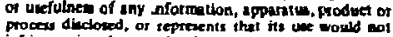
process diectosed, or teproents
infrines vrivalely owned nights.

Models for the edge conditions which are commonly used in tokamak transport codes bave been kept simple partly because of a lack of data. We present a report on an improved model for the particle and energy balance of $\mathrm{e}^{-}, \mathrm{H}_{1}^{+}, \mathrm{H}_{1}^{0}, \mathrm{H}_{2}^{+}, \mathrm{H}_{2}^{0}, 0^{0}, 0^{(1 \rightarrow 8)^{+}}$in the plasme scrape-off region. Experiments should yield the needed data in the near future, and allow us to test the model.

The diffusion of impurities has been stuaied with a neociassical model. The role of 'anomalous spreacing' of the impurity distribution has been studied for the case of Fe.. We presant a model for the expulsion of low- $Z$ (oxygen) impurities for casez where $q(0)>1$, but in which a large shear-Pree region is produced in the plasma core.

1. INTRODUCTION

There are many computer models of tokamak transport (see the surveys by Mercier[I], Dïchs[2], and Hogan[3]) Their treatment of edge effects has been kept relatively simple, In part because there is a scarcity. of relevant data on many of the fundamental wall interaction processes. Typically, the edge values of plasma temperature and density in these codes will be held to some pre-determined value. The inconing fluxes of neutral gas and impurities are prescribed either by qualitetive comparison with fast pressure measurements and line radiation intensities, or else they are chosen to satisfy some overall requirement on the temporal behavior. Examples of the latter are the condition of a fixed total number of particjes, or an axjgen recycling rate equal to the hydrogen rate.

Because there are good prospects for a more detailed examination of some of the fundamental impurity production processes, se have improved the model used in the Oak Ridge Tokamak code to treat edge effects. We nave beer encouraged along these lines by the work preserted by Hotson and Mecracken[4]. Our boundary model is somewhat different, though, and it derives from the treatment of the C-Stelleirator by Hinnov, Bishop, and Fillon $\{5\}$. These authors have modeled the entire stellerator aischarge by solving coupled zerodimensional rate equations for the time evolution of the energy and perticle balance in a pure hyarozen plașna with a temperature arouna 10-50 ev. Far our problen we construct a. model for the time evilution of the energy and densities of electrons, $\mathrm{H}_{1}^{+}, \mathrm{H}_{1}^{\circ}, \mathrm{H}_{2}^{+}, \mathrm{H}_{2}^{\circ}, 0^{\circ}$, $0^{(1-8)+}$ in the region of the tokamak which lies between the 'iast flux suxface, '1.e., that which tiches the Iimiter, and the vacuum chamber wall; In Fig. I we show the generalized geometry. This edge plasma is characterized by the plasma suriace area A and a mean thickness, $\Delta$ defined such tiat the volume of plasma between the last fiux surface and the liner wall is $y_{s}=A_{W} A$. We have chosen oxygen as the only impurity species in the edge plasma solely for simplicity. . The wall chemistry is known to be much more complicated than this and to be imperfactly prescribed. This model is self-consistent, however, in that the production of neutral hydrogen and oxygen by charge exchange, photon and photoelectron desorption, plasma evaporation, thermodesorption and sputtering is calculated using outgoing fluxes provided by our racial transport model. The koundary conditions are then *Research sponsored by the Energy Research and Development Administration under contract with Inion carbide Corporation.

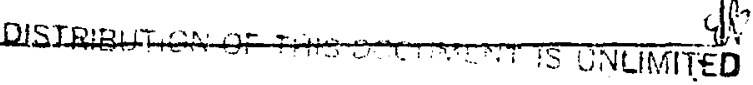


deteruined by sclving the correct particle and energy balance in the scrape-ofe region. These boundary conditions in turn provide the incoming neutral, and impurity fluxes needed-to-describe the transport processes for the radial transpont model.

The second part of this report on our ongoing work is devoted to a study of vartous Iuplinity diffusion rodels. Since the needed data are poorly known for basic desorption and evaporation rates, and since the wall chemistry is complex and poorly kncwn, we will use experimental measurements reported recentiy[6] to test the neoclussical impurity diffusion model. The cases of 'high-z' (iron in our case) and 'low-Z' (oxygen) are presented separate1y.

In the first case we wish to see whether the measurement of central impurity densities provides an estimate of the 'anomalous spreading' which is conmonly added to neoclassical impurity difiusion rates. Since we treat a low-current case, there is probably no significant charge excharge sputtering, so we ignore this source in the calculation.

In the secund case, we exarine the interplay between a iarge rlux of oxygen ( $y_{0} \sim$ $2 \cdot 10^{15} \mathrm{~cm}^{-2} \mathrm{~s}^{-1}$ ) and the MHD stability of the tokamak. For a case where $\mathrm{q}(0)>1$ we find that fluxes of this magnitude can excite strong MD activity by providing a core region of low shear. (This can also provide a mechanism for the strong disruptive instability[7] and would explain why the stability boundaries against disruption are narrowed when the vacuum vessel is pooily cleened.) We will ciscribe the model for boundary eff'ects in Sect. 2. Section 3 describes the neoclassical diffusion studies of iron and oxygen.

\section{BOUNDARY MONEI}

We wish to consider the complex region between the 'last flux surface' and the vacuum chamber wall. The plasma (by which we shall mean the hot core plasma) is treated by the tokanak simulation model we describe in the Appendix. This model provides the sources or Iosses which drive the plasina/iall Interaction from the plesma side; they are the processes we will treat in the model described here.

We will assume that the interface region carries no current an that the required electromasnetic properties are completely specified by proviaing tive poloidal and toroidal magnetic fielis.

The rate equations we solve for the edge region are as foliows.

2.1 Dersity Ecustions: Fydrogenic

$\frac{d N_{1}^{+}}{d t}=N_{e} N_{0} S_{2}+N_{e}{ }^{O N} S_{3}+2 N_{e} S_{2}^{O} S_{5}+N_{e} N_{2}^{+} S_{6}-N_{p} N_{2}^{O} S_{8}-L_{1}^{+}+F_{1}^{+} / \Delta$

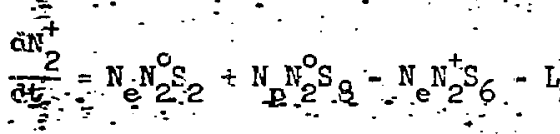

disto

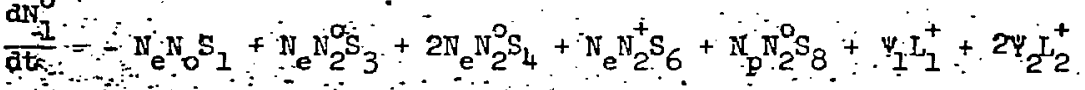

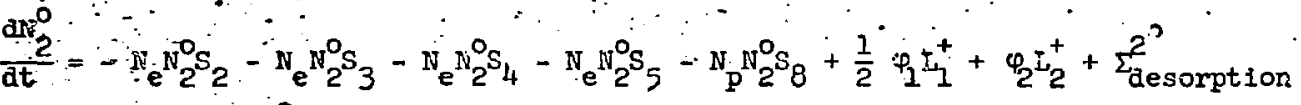

$\mathbf{N}_{e}=\mathrm{N}_{\mathrm{p}}+\mathrm{N}_{2}^{+}+\sum_{k=2}^{9}(\mathrm{k}-1) \mathrm{N}_{\mathrm{O}_{k}}$

$I_{1}^{+}=\frac{N_{p}}{T} \quad I_{2}^{+} \equiv \frac{N_{2}^{+}}{T} \quad I_{1}^{+}=$plasma proton $f_{2}^{+} a x$ 


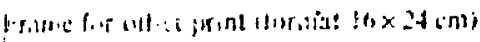

3

i ${ }^{\prime} \gamma_{1,2}$ : Probability of $\mathrm{H}_{2}^{\circ}$ desorption by wall impact of $\mathrm{H}_{1}^{4}$ and $\mathrm{H}_{2}^{+}$, respectively. (See Glossary for other terms. The relevant rates (S) are described in Table I.).

I. Density Equations: Oxygen

$$
\begin{aligned}
& \frac{1}{N_{e}} \frac{d}{d t} H_{k}=I_{k-1} N_{C_{k-1}}+R_{k+1} O_{k+1}-I_{k} O_{k}-R_{k} N_{k}-I_{k}(9 \geq k \geq 2) \\
& \frac{1}{N_{e}} \frac{d}{d t} N_{O_{1}}=R_{2} N_{O_{2}}-I_{1}{ }_{O_{1}}+\Sigma_{\text {desorption }}-L_{O_{1}}
\end{aligned}
$$

$I_{O_{k}}$ are the diffusive loss rates for oxygen. The specific models for $\sum_{\text {desorption }}^{20}$ and. $\Sigma_{\text {desorption }}$ will be discussed where they are relevant. $I_{k}, R_{k}$ are the ionization and reconbination rates.

3.3 Electron Energy Equation

$$
\begin{aligned}
& \frac{d}{d t}\left[\frac{3}{2} N_{e} T_{e}\right]=P_{\text {core plasma }}-N_{e} N_{0} S_{1} E_{1}-N_{e} N_{2}^{O} S_{2} E_{2}-N_{e} N_{2}^{O} S_{3} E_{3}-N_{e} N_{2}^{O} S_{4} E_{4}-N_{e} N_{2}^{O} S_{5} E_{5} \\
& -\mathrm{N}_{e} \mathrm{~N}_{2}^{+} \mathrm{S}_{6} \mathrm{E}_{6}-\mathrm{N}_{e} \mathrm{~N}_{0} \mathrm{~S}_{2 x}\left(1.08 \mathrm{E}_{L \alpha}\right) \\
& -\mathrm{H}_{\mathrm{e}} \mathrm{N}_{\mathrm{O}} \mathrm{S}_{3 \times}\left(0.65 \mathrm{E}_{\mathrm{L \theta}}+0.52 \mathrm{E}_{\mathrm{HB}}\right) \\
& -N_{e} N_{0} S_{4 x}\left(0.51 E_{H Y}+0.33 E_{H \beta}\right) \\
& -3 \cdot 10^{-31} z_{\text {eff }} N_{e}^{2} \mathrm{~T}_{e}-1.53 \cdot 10^{-19} \frac{\mathrm{N}_{e} \mathrm{~N}_{p}\left(\mathrm{~T}_{e}-\mathrm{T}_{p}\right) \ln \Lambda}{\mathrm{A}_{\mathrm{H}} \mathrm{T}_{\mathrm{e}}^{3 / 2}} \\
& -7.7 \cdot 10^{-20} \frac{\lambda_{0} N_{e}^{+}\left(T_{e}-T_{2}^{t}\right) \ln \Lambda}{A_{e} 3 / 2} \\
& -\frac{3}{2} \frac{\dot{N}_{D} T}{T}-\frac{3}{2} \frac{N_{2}^{+T} e}{T^{T}}-N_{e} N_{2}^{O}\left(S_{2}+S_{3}+S_{4}+S_{5} W_{X H}\right. \\
& \text { - lINE - P }
\end{aligned}
$$

where

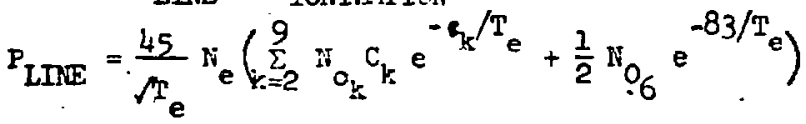

$$
\begin{aligned}
& c_{k}=(16,18,19,20,12,575,655) k=2,8 \\
& c_{k}=(1,1,1.5,1.25,1.1,1.25, .75) k=2,8 \\
& \because z_{\text {eff }}=\sum_{k=1}^{2}(k-1)^{2} \mathrm{~N}_{k} / N_{e}
\end{aligned}
$$

3.4 Hvirogenic Energy. Equations

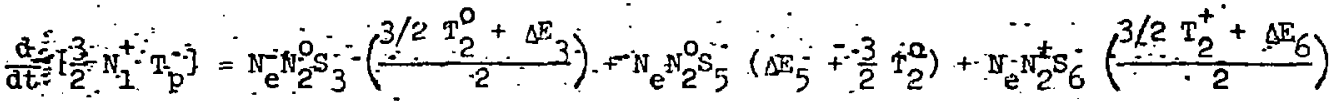

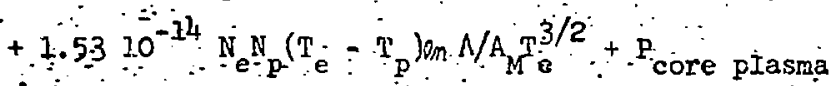

$$
\begin{aligned}
& -3.310^{-18}{ }_{\mathrm{p}} \mathrm{N}_{2}^{+}\left(\mathrm{T}_{\mathrm{p}}-\mathrm{T}_{2}^{+}\right) \ln \Lambda /\left(\mathrm{T}_{\mathrm{p}}+\mathrm{T}_{2}^{+} / 2\right)^{3 / 2} \sqrt{\mathrm{A}_{\mathrm{MI}}} \\
& -\frac{3}{2} N_{p} T_{p} / T+N_{e} N_{2}^{O} S_{1} \frac{3}{2} T_{l}^{O}-N_{p} N_{l}^{O} S_{T} \frac{3}{2}\left(T_{p}-T_{1}^{O}\right)-N_{p} N_{2}^{O} S_{\delta} \frac{3}{2} T_{p}
\end{aligned}
$$

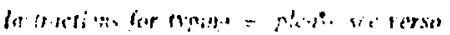




$$
\begin{aligned}
& \frac{d}{d t}\left(\frac{3}{2} N_{2} T_{2}^{+}\right)=N_{e} N_{2}^{O} S_{2}\left(\frac{3}{2} T_{2}^{O}\right)=N_{e} H_{2}^{+} S_{6}\left(\frac{3}{2} T_{2}^{+}\right)+N_{p} N_{2}^{O} S_{8}\left(\frac{3}{2} T_{2}^{O}\right)+N_{2}^{+} N_{2}^{O} S_{4} \frac{3}{2}\left(T_{2}^{O}-T_{2}^{+}\right) \\
& \because+7.710^{-20} \mathrm{~N}_{\mathrm{e}} \mathrm{N}_{2}^{+}\left(\mathrm{T}_{\mathrm{e}}-\mathrm{T}_{2}^{+}\right) \text {en } \mathrm{NA}_{\mathrm{M}} \mathrm{T}^{3 / 2} \\
& +3.310-18 \mathrm{~N}_{\mathrm{p}} \mathrm{N}_{2}^{+}\left(\mathrm{T}_{\mathrm{p}}-\mathrm{T}_{2}^{+}\right) \ln N\left(\mathrm{~T}_{1}+\frac{\mathrm{T}_{2}^{+}}{2}\right)^{3 / 2} \mathrm{~A}_{\mathrm{M}}-\frac{3}{2} \mathrm{~N}_{2}^{+} \mathrm{T}_{2}^{+} / \tau \\
& \frac{d}{d t}\left(\frac{3}{2} N_{I}^{O} T_{1}^{O}\right)=-N_{e} N_{0} S_{1}\left(\frac{3}{2} T_{1}^{0}\right)+N_{e} N_{2} S_{3}\left(\frac{3}{2} T_{2}^{O}+\Delta E_{3}\right) / 2 \\
& +N_{2} N_{2}^{O} S_{4}\left(\frac{3}{2} T_{2}^{0}+\Delta E_{4}\right)+N_{e} N_{2}^{+} S_{6}\left(\frac{3}{2} T_{2}^{+}+\Delta E_{6}\right) / 2 \\
& +N_{p} N_{0} S_{7} \frac{3}{2}\left(T_{p}-T_{1}^{0}\right)+N_{p} N_{2}^{0} S_{8}\left(\frac{3}{2} T_{i}\right)+\Psi_{1} \frac{N_{p}}{T}\left(\frac{3}{2} T_{W}\right) \\
& +2 \psi_{2} \frac{N_{2}^{+}}{T}\left(\frac{3}{2} T_{W}\right)-\frac{3}{2} N_{0} T_{I}^{\circ}\left(I-R_{E}\right) / \tau_{W} \\
& \frac{d}{d t}\left(\frac{3 N_{2}^{\circ}}{2} T_{2}^{\circ}\right)=-\frac{3}{2} T_{2}^{O}\left[N_{e} N_{2}^{O}\left(S_{2}+S_{3}+S_{4}+S_{5}\right)+N_{p} N_{2}^{O} S_{8}\right] \\
& +N_{2}^{+} N_{2}^{O} S_{9} \frac{3}{2}\left(T_{2}^{+}-T_{2}^{O}\right)+\frac{N_{P}}{T} \frac{1}{4} T_{W}+\Psi_{2} \frac{N_{2}^{+}}{T} \frac{3}{2} T_{W}-\frac{3}{2} N_{2}^{O} o_{T}^{O}\left(I-R_{T}\right) / \tau_{W}
\end{aligned}
$$

The reaction rates $S_{1}$ through $s_{9}$ and $s_{2 x}, S_{3 x}, s_{4 x}$ are listed in Table $I$. These include processes for ionization, excitation, dissociation, and charge exchange. The $L_{1+}$ and $\mathrm{L}_{2+}$ are particle loss rate terns which" also carry an energJ loss. The corfinement time is taken to be Bokm or Pfirsch-Schliter (whichever is shorter) for the scrape-off plasma. The protons diffusing to the wall recombine to return os $H_{1}^{0}$ with probability ${ }_{1}$ and as $H_{2}^{\circ}$ with probability $a_{1}$. Similarly, the $\mathrm{K}_{2}^{+}$ions diffusing to the wall recombine as $\mathrm{H}_{1}^{\circ}$ with probability $\Psi_{2}$ and as $H_{2}^{0}$ with probability $\varphi_{2}$.

We assure that the oxygen equilibrates fast enough so that the proton and oxggen ion teraperatures are equil. This ellminates the need for a separate oxygen energy equation.

These equations are calculated in the followng way. An initial value is given to begin. The rajial transpozt madel conputes the appropriate fluxes end the boundary calculation is. then moved along from $t$ to $t+\Delta t$. These boundary values are then used to compute the radial trenstort for the rext timestep.

F@gure:-2 shös a typicel calculeted time evolution of the computed boundary quantities: We assune a descrption yield $\sim 0.005$ stoms/photon for $100 \mathrm{~kW}$ of $1032 \AA$ म radiation (OVI). The calculation-neglects-all other procesises, and starts at $t \fallingdotseq 0$. As oxygen is evolved from the surface, the electron density rises and temperatures drop to a few eV.

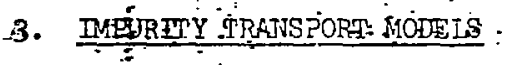

Wé may first discuss the transport of impurities by decoupling the production processes from the calculation. For present experiments there are laser Thomson scattering measurements which allow reasonable estimates of densities and temperatures near the edge. Also, the neirtral transport physics is sufficiently straight forrard that, with a proper cylindrical model such as XSDRN[8], one may calculate the edge neutral density once the central charge exchange flux is know. (This latter technique is valid, of course, only. Wher the tischarde is jrom to be doninated by a angle low-z species, such as oxygen, for which some quantitative estinate of the proton density is possible.) 
Thus, we will treat impurity transport processes in this section by applying the usurl edge conditions and using experimental estimates for the neutral and inpurity influxes. We will discuss two casea: diffusion of iron ('high 'z') and oxygen ('low' $\mathrm{Z}^{\prime}$ ).

\subsection{Diffusion of Iron}

We will discuss simple neoclassical transport of a 'high-z' impurity (iron in our case) to investigat: the magnitude of anomalous spreading which should be added to the neoclassical impurity diffusion equations to match the experimental results.

The impurity transport model is discussed in the Appendix. As an edge condition we will assume that there is no sputtering of the wall by charge exchange neutrals. Further we will study the plateau phase of discharge, reported by the TFR group[6], essuming that there are $2 \times 10^{10} \mathrm{~cm}^{-3}$ of iron atoms present initially, discributed uniformly in radius. We take an initial central density of $3.5 \times 10^{13} \mathrm{~cm}^{-3}$ and a fixed boundary density of $10^{13}$ $\cos ^{-3}$

Figure. 3 shows the evolution in tine of $\mathrm{n}_{\mathrm{Fe}}$. Although the rise of $\mathrm{n}_{\mathrm{Fe}}$ (0) in time is substantial, this effect is due solely to rearrengement of the essumed initial.2. $x^{10} \mathrm{~cm}^{-3}$; density; $\mathrm{N}_{\mathrm{Fe}}$ (the total number of iron atoms) is constent (we have assumed that there is no sputtering). The rise in central density is not evidence of sputtering by itself, since the neoclassical diftusion process pushes the original number of impurities into a small volume, thus substantially increasing the number density without increasing the number.

Figure 4 shows the time evolution of $n_{F e}(0), z_{e f f}^{F e}(0)$ and $z_{F e}$ for various values: of $\alpha$, where the anomalous spreading diffusion roefficient is taken to be $\alpha p^{.}$Choosing $\alpha \sim 0.3$ will reproduce the observations.

\subsection{Diffusion of oxrgen}

We examine the same cese, but now using only oxgrgen. The flow rate $\left.\psi^{0} \sim 2 \times 1\right)^{25} \mathrm{~cm}^{-2}$ $8^{-1}$ reported in $[6]$ is assumed ior inflowing oxygen at the ecige. Figure 5 (a-d) sinows tbe evolution of $T_{e}, j_{z}, q$, oxygen density profiles as a function of $t$ ine. We note that, as new oxggen flows in, the raciative losses cause a strong contracti $x$ of the current. chanel. The edge $T_{e}$ drops and; because of the resultinf incresse in resistivity, so does the curient density. Since the total current is prosraned to be constant in the plategu phase Aof the experiment, the current density must increese elsewhere in the volume. The nagnetic diffusion time is a maximum on exis, and so the beherior shown in Eig. 5 is the result: - there results an off-axis pear in $j_{g}(r)$. The $q(-)$ profile. shows a local rinimum, and so the plasma is susceptible to a wide variety hydromagnetic instabiljties.

This implies that our radial transpet modcl sannot supply an accurate description: fast time scale MHD processes will surely flatten the $j_{z}$ profile and produce a broba shearfree eentral: $q(r)$ profile.

The effect of this mixing process will be to produce a steady-state in the impurity belance: The turbulent mixing will produce the efflux of fuily stripped oxygen atcms which is needed to balence the -incoming lower ionized states. - We note that $q(0)>I$. Thus the conditions of low shear which sre provided by the high jmpurity influx can be present for high $q(a)$. It follows that the narrowing of stability bouncaries against strong disruption should be very sensitive to the state of cleanliness of the wall in this model as it is doserved to be "in prectice. 
APPENDIX

Particle Baiance:- We treat the electroin balance, using charge neutrality to determine the proton density.

$$
\frac{\partial}{\partial t} N_{e}(r, t)+\frac{1}{r} \frac{\partial}{\partial r}\left(r N_{e} V\right)=N_{e} N_{0}\langle\sigma v\rangle_{\text {Ion }}+\Sigma_{\text {INP }}+\Sigma_{\text {BEAM }} \equiv R+\Sigma_{\text {BEAM }}
$$

Electron Energy Balance:

$\frac{3}{2} \frac{\partial}{\partial t}\left(N_{e} T_{e}\right)=\frac{1}{r} \frac{a}{\partial r}\left[r\left(q_{e}+\frac{3}{2} N_{e} V_{e}\right)\right]-3 \frac{m_{e}}{m_{p}} \frac{T_{e}-T_{p}}{T_{e}}+E j+R T_{0}-P_{r a d}+Q_{I n j}^{c}$

The electron energy balance ireats the conduction $\left(q_{e}\right)$, convection $\left(\frac{3}{2} N_{e} V_{e}\right)$, electronFroton thermal equilibration, ohmic heating, the source of cold electrons, radiative losses and auxiliary herting. The calculations for $q, v, E, j, P_{\text {Rad }}$, and $Q^{e}$ Inj are discussed, for example, by Hogan [3].

Proton Energy Balance:

$$
\begin{aligned}
\frac{3}{2} \frac{\partial}{\partial t}\left(N_{p} T_{p}\right) & =-\frac{1}{r} \frac{\partial}{\partial r}\left[r\left(q_{p}+\frac{3}{2} N_{e} V_{p}\right)\right]+3 \frac{m e}{m_{p}} \frac{T_{e}-T_{p}}{T_{e}}-s_{p} N_{o}\langle\sigma\rangle_{C X}\left(T_{p}-T_{o}\right) \\
& +Q_{I n j}^{P}+R T_{0}
\end{aligned}
$$

Field Dîfusior: The relevant electromagnetic equations and an 0 hm ${ }^{2} \mathrm{~s}$ lew

$$
\begin{aligned}
& \frac{\partial B}{\partial t}=\frac{\partial F}{\partial r} ; \mu_{0} j=\frac{2}{r} \frac{\partial}{\partial r} \\
& j=E / \pi+j_{B}
\end{aligned}
$$

\section{GLOSSARY OF TERTS}

$N_{e, p}:$ Electron, proton density

V: Ambipolar a:ffusicn velocity (defined below)

$N_{0}:$ Density of ieutrals

(ov) ion - . Rate of electron impact Lonization of neutral $\mathrm{H}$.

$\Sigma_{\text {MP }}:-$ Sousse of: electrons from Impurity stripping

$\Sigma_{\text {BEAM }}:$ Source of electrons from injected beam

Te

q

$\dot{m}_{\dot{c} ;} \mathbf{p}$ Electronj proton masses.

-Telectron-ion-scattering tire $=3 \sqrt{n} e^{3 / 2} e^{3 / 2} \sqrt{2} \pi e^{4} v_{p}$

$\left(\lambda^{-}=\right.$Coulomb logarithm, e: electron charge)

E: Longltudinal electric field.

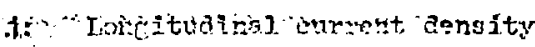

$T_{0}: \quad$ Mean energy of $\mathrm{H}_{0}$ 


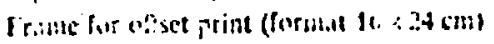

7

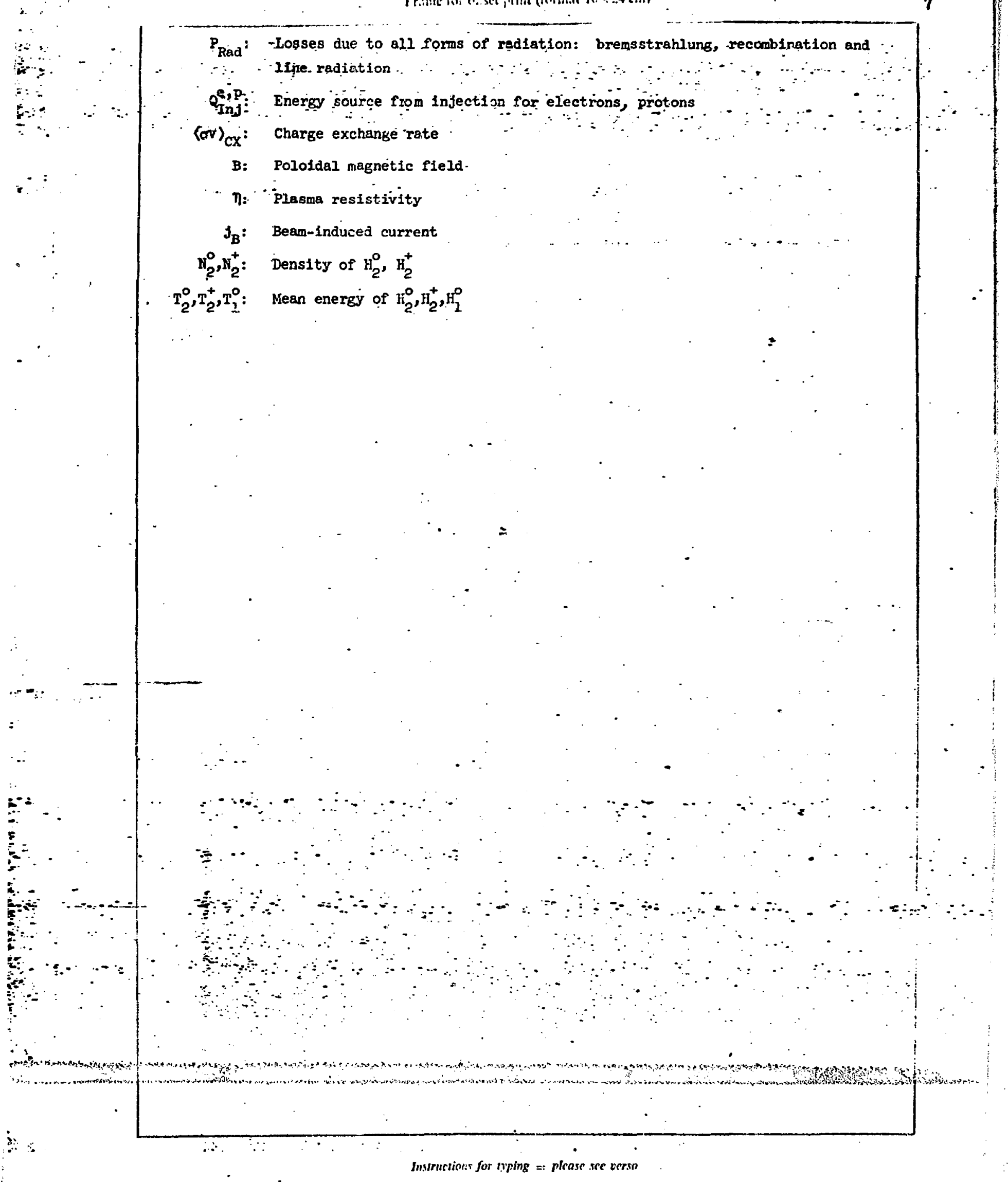


Densities

Densities
Reaction Energy Input

ointpit .

$N_{-}-N_{1}^{0} S_{1}-E_{i}-e+H_{1}^{0} \cdots$

$\because+\mathrm{H}_{\mathrm{i}}^{+}+\mathrm{t}$

$\mathrm{N}_{\mathrm{e}} \mathrm{N}_{2}^{\mathrm{O}} \mathrm{S}_{2} \quad \mathrm{E}_{2} \quad \mathrm{e}+\mathrm{H}_{2}^{0} \quad \mathrm{e}+\mathrm{H}_{2}^{+}+\mathrm{e}$

$\mathrm{N}_{2}^{0} \mathrm{~S}_{3} \ldots \mathrm{E}_{-3}=\mathrm{e}+\mathrm{H}_{2}^{0} \ldots \mathrm{e}+\dot{\mathrm{H}}_{1}^{+}+\mathrm{H}_{3}^{10}+\mathrm{e}$

$\mathrm{N}_{\mathrm{e}} \mathrm{N}_{2}^{0} \mathrm{~S}_{4} \quad \mathrm{E}_{4} \quad \mathrm{e}+\mathrm{H}_{2}^{0} \quad \mathrm{e}+\mathrm{H}_{1}^{0}+\mathrm{H}_{1}^{\mathrm{O}}$

$\mathrm{N}_{\mathrm{e}} \mathrm{N}_{2}^{\mathrm{O}} \mathrm{S}_{5} \quad \mathrm{E}_{5} . \mathrm{e}+\mathrm{H}_{2}^{\mathrm{O}} \quad \mathrm{e}+\mathrm{H}_{1}^{+}+\mathrm{H}_{1}^{+}+e+e$

$N_{e} N_{2}^{+} s_{6} \quad v_{6} \quad e+H_{2}^{+}$

$\mathrm{e}+\mathrm{H}_{1}^{+}+\mathrm{H}_{1}^{0}$

$\mathrm{N}_{1}^{+}+\mathrm{N}_{1}^{0} \mathrm{~S}_{7} \mathrm{E}_{7} \mathrm{H}_{1}^{+}+\mathrm{H}_{1}^{0} \cdot \mathrm{H}_{1}^{0}+\mathrm{H}_{1}^{+}$

$\mathrm{N}_{1}^{0}+\mathrm{N}_{2}^{\circ} \mathrm{S}_{8} \mathrm{E}_{8} \cdot \mathrm{H}_{2}^{+}+\mathrm{H}_{2}^{0} \quad \mathrm{H}_{2}^{0}+\mathrm{H}_{2}^{+}$

$\mathrm{S}_{9} \mathrm{E}_{9} \cdot \mathrm{H}_{2}^{+}+\mathrm{H}_{2}^{\mathrm{O}} \quad \mathrm{H}_{2}^{\mathrm{O}}+\mathrm{H}_{2}^{+}$

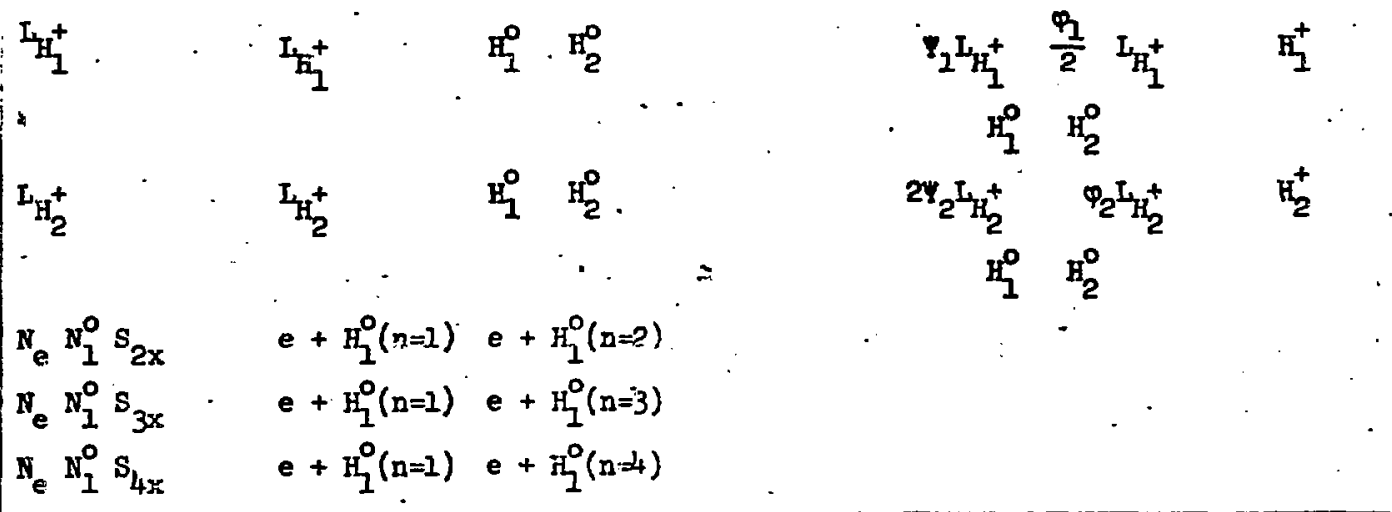

Loss - .

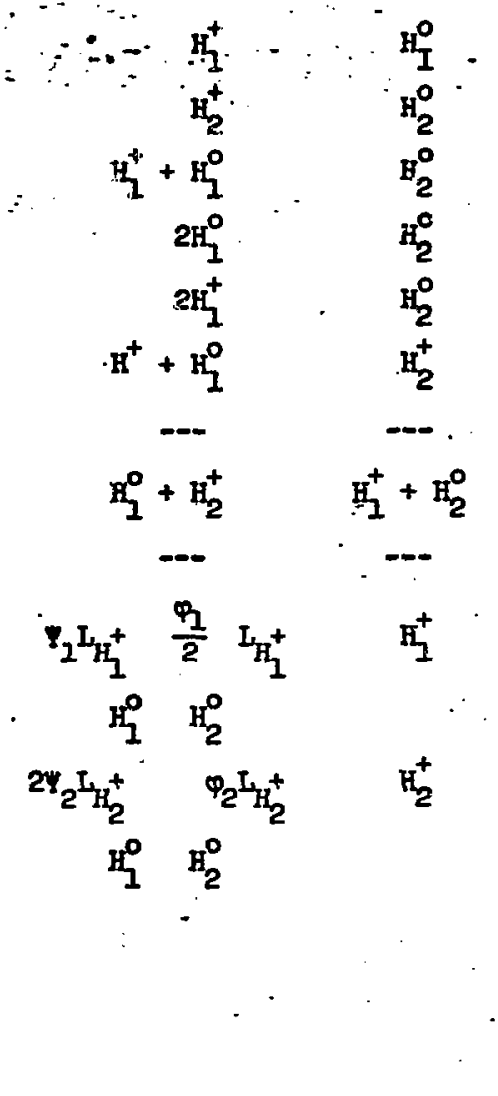


A

[1] MERCIER, $c$; and SOUBBARAMMYY::

merical Models for ? Devices," Rifth European Coni. "iee on Controlied Furs. 1972.

Evolution In Tokamak is Plesina" Physics; Grenoble,

[2] DÜCAS, D. F. FUKTH, H. P:, $2:$ Transport in Tokamak Dische?. Toroidal Conf'inement, ". Garchi:

THERFORD, $\dot{\mathrm{P}}_{0} \cdot \mathrm{H}_{2}, \mathrm{NU}$

ai Calculations of the Radial "Proceedings of the "i... I International Symposium on 1973.

[3] HọGAN, J: T., "Multifiufù Tol: $\therefore$ Transport Models," v. 16: Computer Applications .. Controlled Fustion Rese

;is of Computational Physics, $\therefore$, Academic Press (in press).

[4] HOTSON, E., and MCCKACKEN, G. .., "Investigation of P1: a Self-Consistent Model for t:

Recycling at Surfaces Using J. Nucl. Mater. (to appear).

[5] HINNOV, E., BISHOP, A. S., aw: : iLLON, H., Jr., "Compit. Stellerator Ohric Heating Dis: . es in Hydrogen, "Plas: MARCUS, $F$. B. and ATTENBERGLi?, $\therefore$ E., "Tokamak Startup

Description of the C. Physics 10:291 (1968), also $\therefore e$," private comunication.

[6] TFR Group, "Line Radiation in th: Visible end Ultraviol, . in TFR Tokrmek Plasmas," Nucl. Fus. 15:1053 (1975).

[7] MIRNOV, S. V and SEMENOV, I. $\because$. "Observation of the $F$; Instability in a Tokamak Devic ," Sixth IAEA Conference trolled Nuclear Fusion, Berchti : aden, 1976.

Structure of a Disruptive Plasms Physics and Con-

[8] CRUNE, E. C., et al., "The NU: :.. "i Code," private connu. "A. User's Manual for ANISN," $C$. Ridge AEC R and D Repo.

:stion and ENGLE, พ. พ., Jr., R-1693, 1966.

[9] RUTHERFORD, P. H., "Impurity L'...usion in the Pfirsch-S: üter Regime," Phys. Fluids 17:1782 (1974) and MOORE, T. B. and HivTON, F. L., "Imp...: ty Transport in the BananaPlateau Regime," Nucl. Fus. I4:609(1974). 


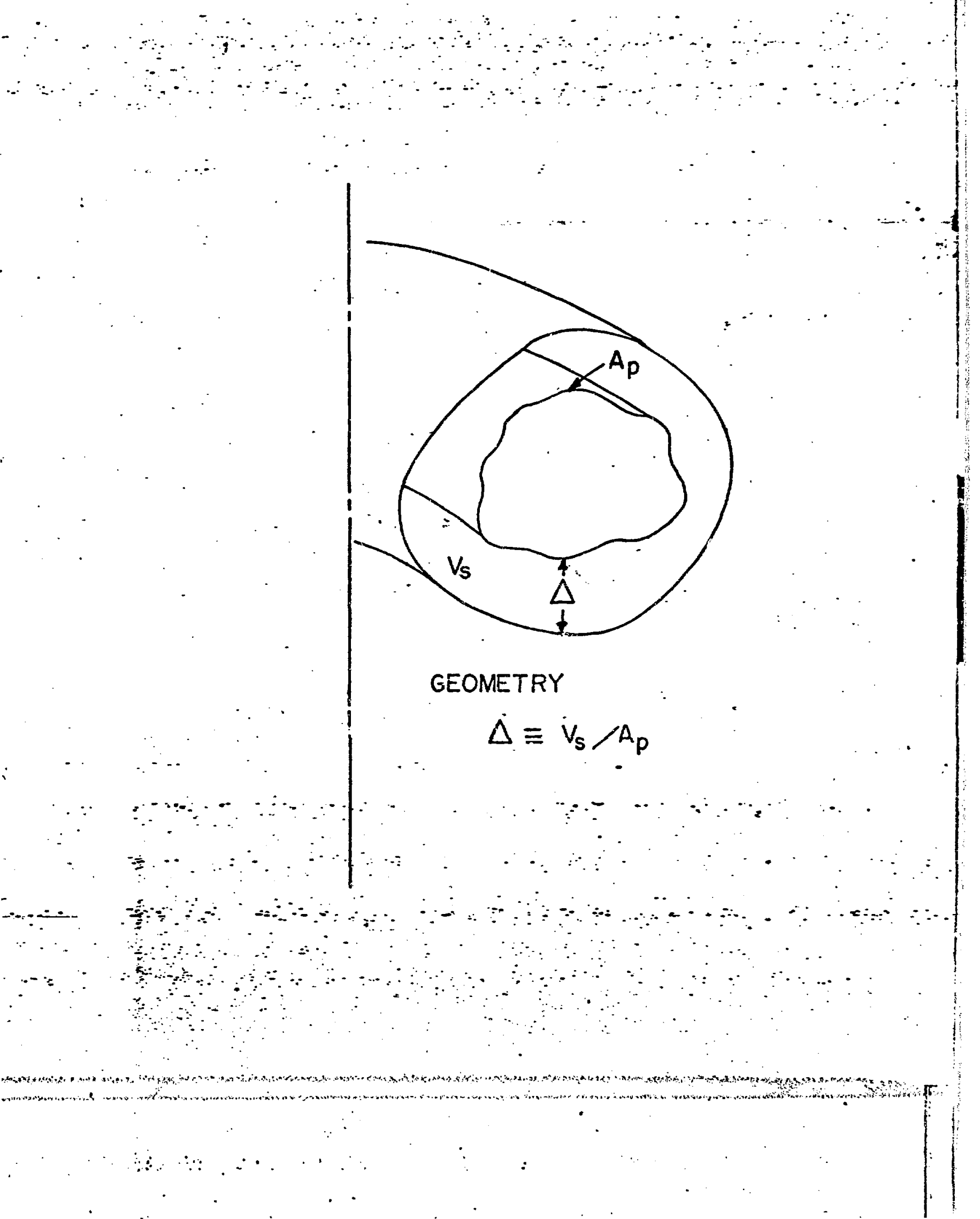


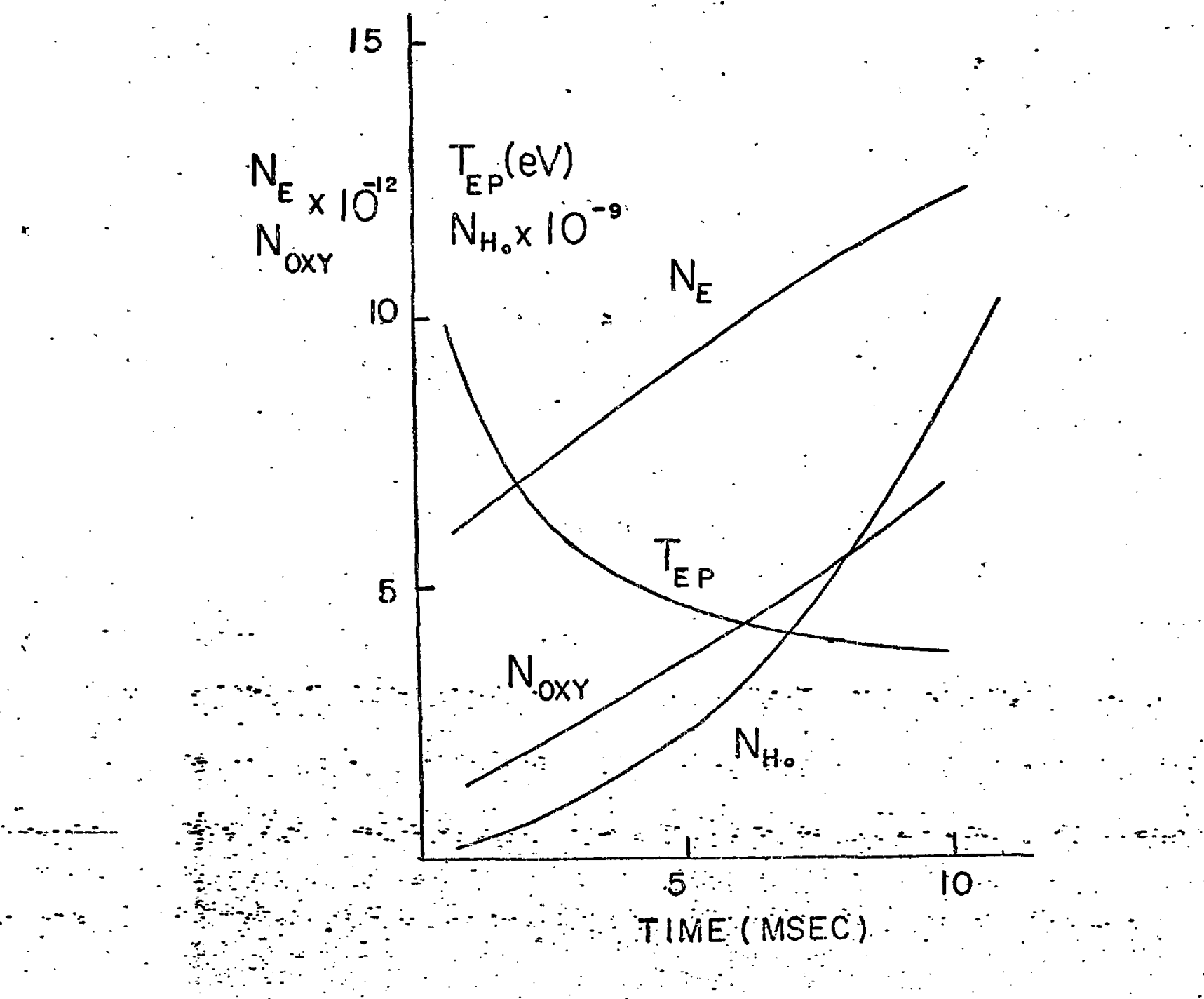



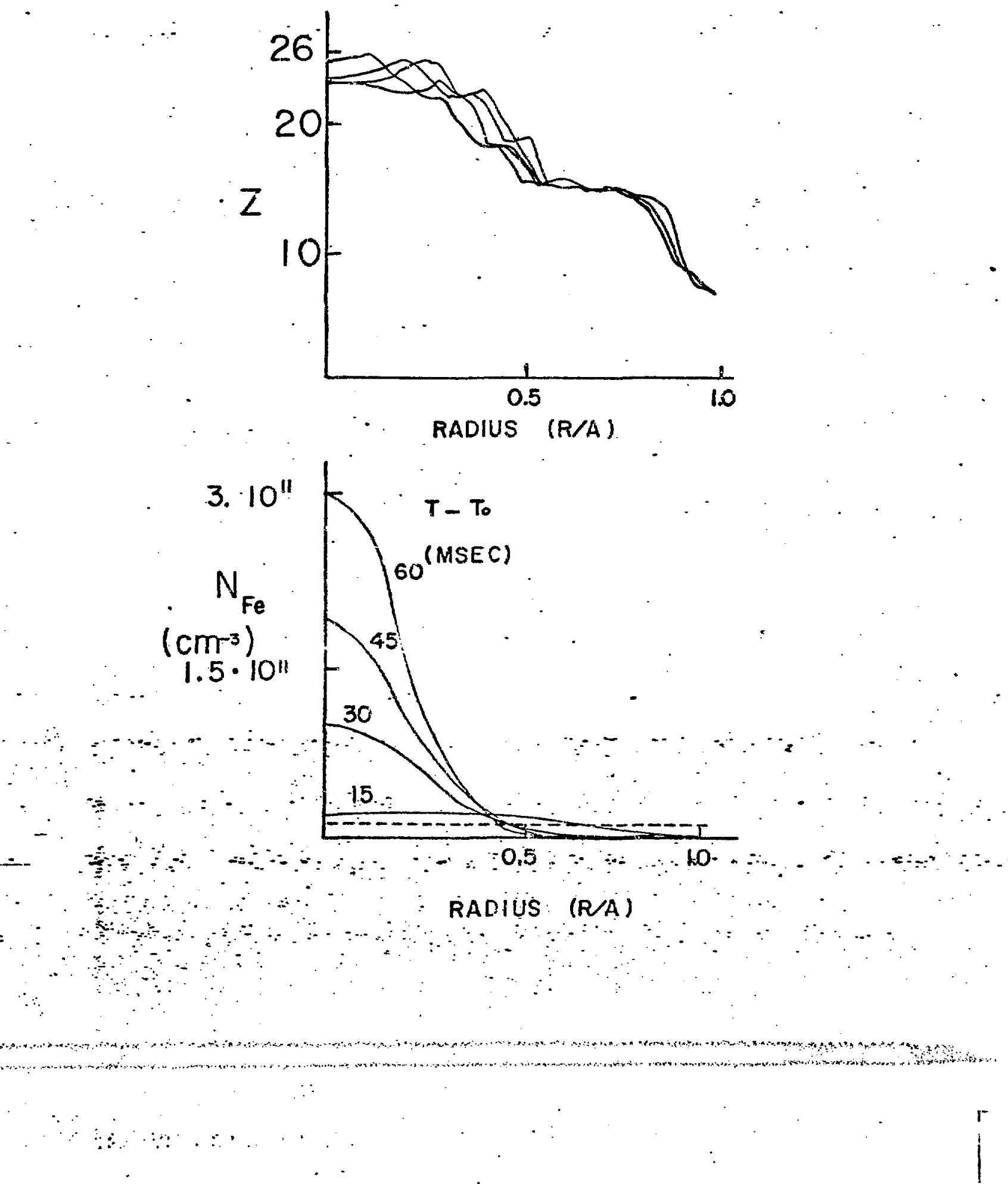


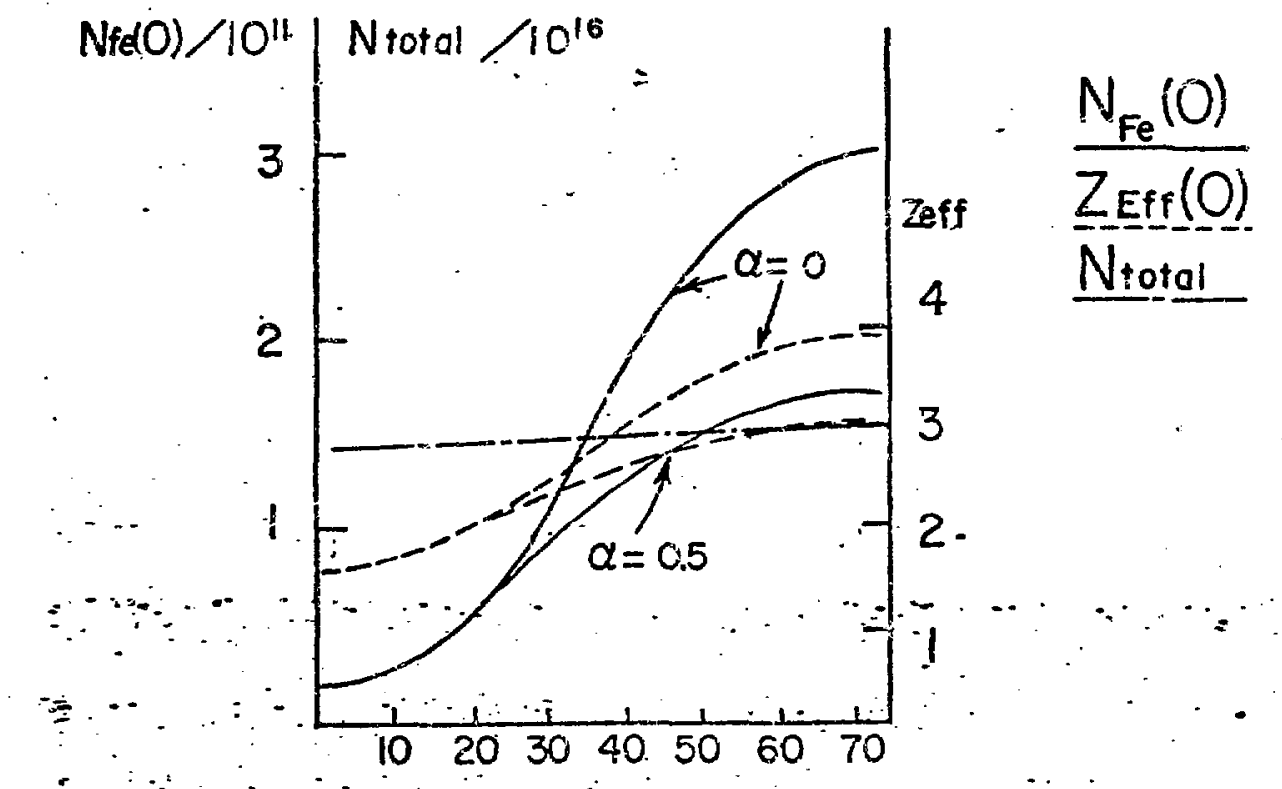

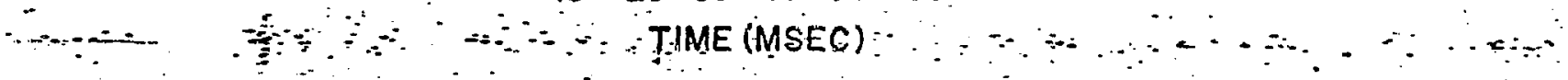



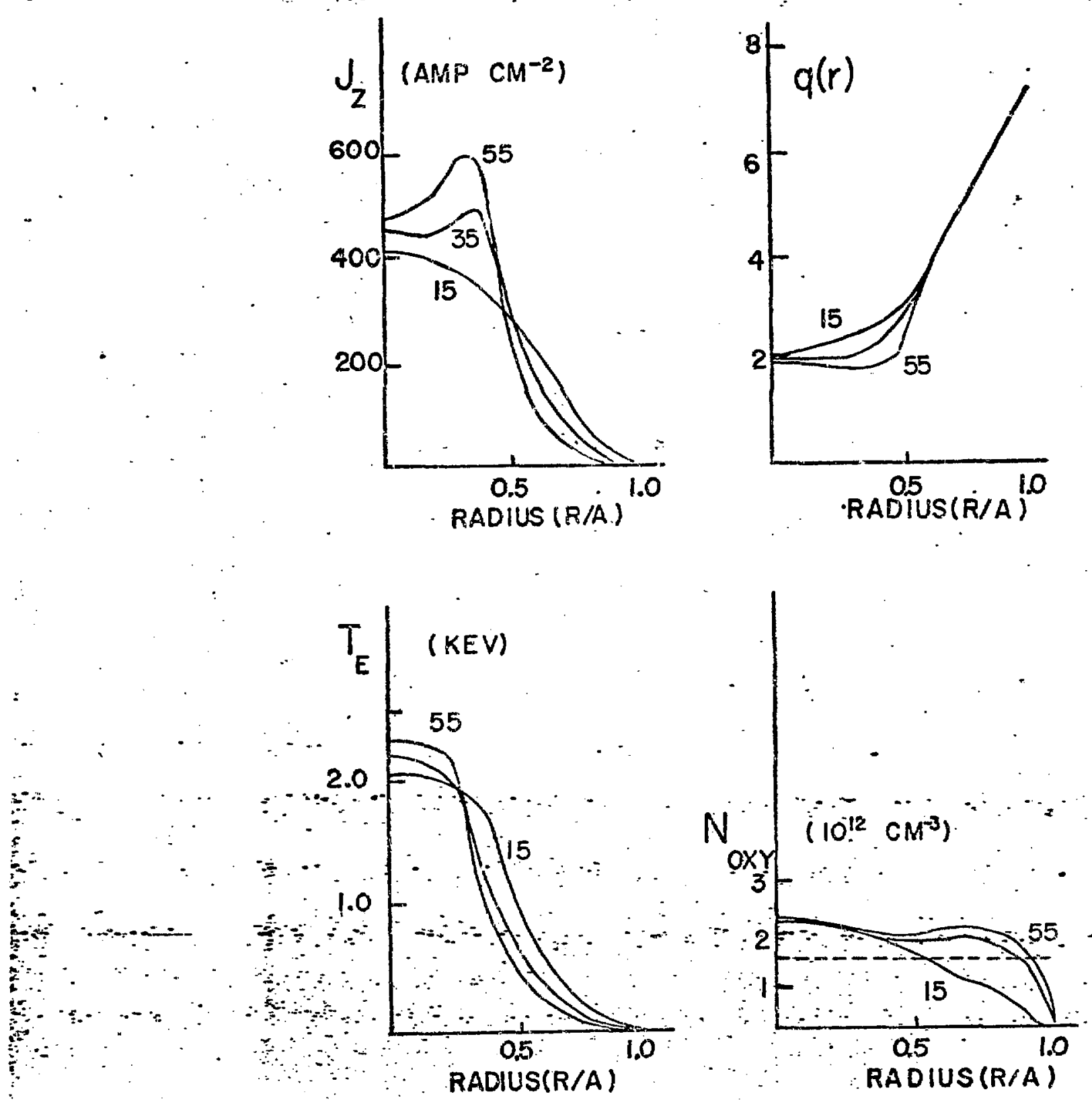